\title{
Con la tercera España. Luigi Sturzo, la Iglesia y la Guerra Civil Española
}

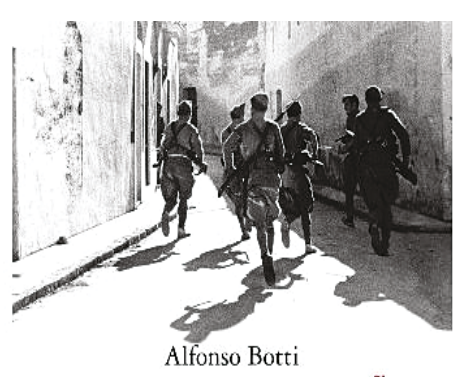

CON LA TERCERA ESPAÑA



FICHA BIBLIOGRÁFICA

Alfonso Botti, Con la tercera España. Luigi Sturzo, la Iglesia y la Guerra Civil Española. Madrid, Alianza Editorial, 2020, 306 páginas, ISBN 978-84-9181-856-4

\section{Pere Fullana Puigserver I Universitat de les Illes Balears}

El PROFESOR Alfonso Botti SE HA CONSOlidado durante los últimos treinta años como uno de los hispanistas italianos de referencia, y en su entorno se ha generado una historiografía de impacto, especialmente en el ámbito de la historia contemporánea. Destaca como dinamizador de proyectos de investigación y como impulsor y director de publicaciones, entre ellas Spagna Contemporanea o Modernism. En esta obra, Botti se confirma como uno de los grandes referentes de la historiografía religiosa contemporánea en España, con trabajos sobre el modernismo, el nacionalcatolicismo, la iglesia durante la II República o el compromiso católico durante la Guerra Civil. El texto titulado Con la Tercera España puede definirse como «el libro después del libro», en la medida que su contenido es el resultado del análisis y del estudio de la publicación de 2012 de Luigi Sturzo e gli amici spagnoli, a cargo del propio Botti. 
La publicación que presentamos encaja en el marco de la tercera España (Paul Preston) y la tercera Cataluña (Arnau González), a la luz de la obra de Miquel Batllori y Victor Manuel Arbeloa, Alfonso Álvarez Bolado e Hilari Raguer, y llega a su plenitud en el contexto de la Asociación Española de Historia Religiosa Contemporánea, promovida por Feliciano Montero, ahora liderada por Julio de la Cueva.

Cuanto al contenido, la obra se divide en cinco capítulos y unas conclusiones. En el primero trata la crisis del sistema de la Restauración en España (1919-1930), con el eco de las políticas demócrata cristianas en España, a la luz de las aportaciones de Luigi Sturzo y la fundación del Partito Popolare Italiano (PPI) en 1919; el segundo se centra en la Segunda República (1931-1936), siempre a partir de la lectura y la perspectiva que ofrece el diálogo que Sturzo sostiene con sus amigos españoles, y el debate que suscita su experiencia como opositor al fascismo y la inexistencia de una posición democrática en el tablero del catolicismo occidental. Entre 1919 y 1936 en el seno de los catolicismos europeos crece un pequeño colectivo de intelectuales y activistas comprometidos con la democracia. Una minoría frágil y sospechosa como representante de la denominada herejía democrática, heredera del primer catolicismo liberal.

El tema central del libro se desarrolla en los tres últimos capítulos, todos ellos dedicados íntegramente a la Guerra Civil. El tercero nos sitúa en el escenario de los primeros meses de la contienda, un tiempo marcado por la violencia anticlerical, los asesinatos y la represión despiadada en los territorios dominados por el ejército golpista. Lo acontecido durante estos meses va a generar relatos diversos, pero en líneas generales reforzó la institución eclesiástica española contra la República. Con el vacío dejado por la Nunciatura Apostólica, el control de la jerarquía quedó en manos de Isidro Gomá, arzobispo de Toledo desde 1933. En el escenario la Iglesia española aparece como una institución víctima y mártir, y como cómplice y legitimadora del golpe de estado. Rápidamente Sturzo entiende que la Iglesia debía desmarcarse de los sublevados y comprometerse con la paz, En el primer invierno de 1936-1937, Sturzo toma partido a favor de la paz, y persuade a intelectuales con ascendencia social y política, para abrir mesas de diálogo. En paralelo se produce la internacionalización del conflicto y la internacionalización de la concordia, el impacto de los primeros meses no dejaba indiferente a nadie, aunque las heridas en uno y otro bando eran difíciles de curar y los puentes inexistentes.

Siguiendo el hilo, en el cuarto capítulo, el autor nos cita en el segundo año de guerra, el 1937. Un tiempo simbólico y decisivo, con dos frentes, la trinchera y la propaganda, también para la Iglesia española, con Gomá al frente, apoyado por la Santa Sede. 1937 fue el año de la publicación de la Carta Colectiva del Episcopado español, pero también de la convocatoria de los principales Comités internacionales de Paz. Con este telón de fondo, Botti nos adentra en la alternativa que se genera en el entorno de Luigi Sturzo, los debates y las propuestas que generan intelectuales, políticos y eclesiásticos para conseguir que la tragedia no se concentre sobre una parte de los contendientes. El culto público, a pesar de los intentos de Negrín, Irujo, Rial o Vidal i Barraquer no obtuvo el apoyo de la Santa Sede, ante las presiones de la iglesia nacionalista española que, a medida que avanzaba el año, iba ganando posiciones en la agenda de guerra. Desde la perspectiva de Sturzo y sus amigos, la opinión pública interna- 
cional, proveniente de un catolicismo democrático, abierto y conciliador en Europa, quedaría tocada a mediados del mismo 1937.

Finalmente, el autor dedica el quinto capítulo al último año de guerra, 1938-1939, caracterizado por el acoso final, el camino a la victoria, con vencidos, pero sin vencedores morales, sin gloria, sin consenso, sin prestigio, sin aquellos valores que decían defender. La Iglesia, en conjunto, vive el momento de mayor distanciamiento del liberalismo democrático y sostiene argumentos de perfil netamente autoritarios, con el apoyo de la Santa Sede y la legitimidad de Pio XI, un papa autoritario, bien visto en España, cercano a Alfonso XIII, a la dictadura de Primo de Rivera y a los obispos. Una jerarquía que reproducía los valores hispánicos de corte tradicional, representante de un catolicismo integrista y antiliberal. Incluso Pio XII acabará apostando por los vencedores. Al final, Gomá será el perdedor entre 1939-40. Morirá desquiciado, traicionado y defraudado.

El libro plantea cuestiones de calado, siempre a partir de la riquísima red de relaciones que ha venido tejiendo Sturzo en España. Esencialmente, el libro subraya el prestigio y la credibilidad que tiene el fundador el PPI para un colectivo de católicos españoles muy diverso, que lucha a contracorriente, un catolicismo democrático, libre, pero frágil y sin eco suficiente en una sociedad católica sin clase media. En general se trata de individuos que han evolucionado en el seno de una burguesía democrática, abierta, formada, vinculada al mundo de lo público, independiente de obispos y colectivos políticos y clanes económicos. Luigi Sturzo nos descubre las fragilidades del catolicismo liberal hispano. Un catolicismo con una larga tradición al que el integrismo siempre trató de menospreciar y de descalificar. Un catolicismo que el propio sistema de la Restauración, dominado por caciques, notables, militares y clérigos, había sacrificado al considerar que su presencia crítica podía hacer fracasar sus intereses y proyectos.

Este constante menosprecio impidió apoyos y dividió al catolicismo más modernizador y abierto, poniendo en evidencia la debilidad del catolicismo social y sus prácticas políticas. De una forma contundente, el autor destaca la fragilidad de la sociedad civil católica española y la escasa autonomía de las redes y los agentes católicos al final de la Restauración, la dictadura y en especial durante la Segunda República.

En el libro queda muy bien diseñado el mapa de los comités internacionales destinados a conseguir la paz, la reconciliación y la fraternidad entre españoles, pone de manifiesto que los contemporáneos tenían plena conciencia de la internacionalización del conflicto español y del ensayo que se estaba produciendo en el territorio, como preámbulo de lo que estaba a punto de llegar. A su vez, nos presenta el encuentro entre los católicos democráticos europeos, el compromiso de las principales publicaciones católicas no integristas, con el conflicto como telón de fondo.

El autor se aleja de la idea de que la Tercera España proviene de la periferia del Estado, propiciada por los partidos nacionalistas de perfil social cristiano. Ciertamente Sturzo publica en Cataluña, pero sin identificarse exclusivamente con el paradigma catalanista. Sus interlocutores no están asociados a una causa territorial, sino a un compromiso político de calado democrático, una propuesta que Sturzo presenta de una forma moderna, democrática y derivada de una interpretación teológica dinámica y abierta. Desde el espíritu crítico 
y autocrítico que sostiene el fundador del PPI, Botti se muestra especialmente crítico con la Iglesia. Presenta una institución desquiciada, una iglesia -en minúscula- cómplice de los «carniceros franquistas» (en palabras del propio Botti). En aquella España de entreguerras, y en plena Guerra Civil, para los católicos pactar, negociar y transigir era de cobardes. Dicha actitud, sin embargo, contrasta con quienes se mueven en la alta diplomacia internacional y trabajan en la órbita de la internacionalización del conflicto, singularmente para quienes luchan sin descanso para ofrecer una solución negociada y un espacio de reconciliación. El profesor Botti nos presenta la historia vista desde la mirada y el compromiso de Sturzo, un cristiano y un político influyente, aglutinador, que vive en propia carne la ambigüedad humana e histórica. No cabe duda, que Sturzo se siente libre en España, aunque era censurado, cuestionado, mal interpretado, incluso en algunos casos por sus más allegados.

En el contexto de la Guerra Civil, el autor nos invita a visitar los escenarios de la paz, nos presenta a los luchadores alternativos, nos muestra individuos y colectivos que experimentaron la frustración y se considerarán perdedores en el balance general de 1939. En conjunto la obra implementa la constelación de intelectuales, pacifistas cristianos comprometidos con una alternativa que pueda servir de referencia para solucionar el estado en que se halla occidente durante el primer tercio del siglo XX. En torno a la figura de Sturzo, Maritain y tantos cristianos modernos y democráticos, existió un cristianismo que no se cansó de buscar la concordia y creyó en la paz. A la sombra de Sturzo se formó un grupo de acción, que muy posiblemente podría hacerse extensivo a otros colectivos de talante integrador que en sus ámbitos lucharon dentro y fuera del territorio para llegar a una solución negociada. En 1939 no fue posible. Al catolicismo español le faltaba base democrática y a su jerarquía mucho más. Los catolicismos institucionales, dóciles a la Santa Sede, recelosos de la izquierda europea, tampoco apoyaron como era de esperar a quienes intentaban liberar a la Iglesia de componentes monárquicos, conservadores y de valores morales que la secularización y la modernidad habían cuestionado profundamente. En términos generales, el libro muestra el impacto y los valores de quienes querían «ganar la paz», pero para ello tendrían que esperar a 1945, con el nacimiento de un nuevo horizonte europeo. 